\title{
Research on the Development of Rural Tourism Products in the Supply - Side Reform
}

\section{Qiuhong Yang}

China West Normal University, Sichuan, Nanchong, 637000

\author{
Keywords: Rural Tourism Products, Supply-side Reform, Economical Management
}

\begin{abstract}
The supply-side reform of rural tourism products boosts the transformation and upgrading of rural tourism and the tourism poverty alleviation. At present, the supply of rural tourism products in China is more monotonous in product supply and the structure is not reasonable; the products are of high homogeneity; the service quality is not high; the image of tourism destination is not clear enough; the product culture is less rich and the product experience value is not high. Therefore, it is necessary to enrich product categories, optimize the structure of tourism products; create personalized products, enhance product competitiveness; attach importance to the construction of rural tourism professionals and improve the quality of service; strengthen the "cultural tourism" integration of the two industries so as to enhance the culture connotation of products, improve experience of visitors.
\end{abstract}

\section{Introduction}

After nearly 40 years of reform and opening up, China's economic and social development has made tremendous achievements and the people's living standards have been upgraded. The rich people's pursuit of the spiritual and cultural life, promote the rapid development of China's tourism industry, all kinds of tourism product innovation, for the people in the holiday arrangement provides many choices. Thanks to its proximity to the city and the experience of being able to enjoy another lifestyle, the development of rural tourism in China has been rapidly developed in recent years and has become an important choice for people to relax during the weekend. Strong market demand, so that all cities around the country's rural tourism products blossom everywhere, the market has expanded dramatically. However, at the same time, the following up with the wind phenomenon in the development of rural tourism products as well as the experiential problems of rural tourism products and the backward construction of brands have not fully met the diversified needs of tourists. It is imperative to strengthen product development. As far as rural tourism is concerned, rural views are not much different. If we only engage in tourism in rural areas, we can not achieve differentiated competition in fierce market competition [1]. In this situation, more and more rural tourism managers are beginning to seek breakthroughs, drawing on the theory of industrial integration and realizing the integration of rural tourism and other industries so as to promote new rural tourism products and provide tourists with more and richer Choose to improve the competitiveness of rural tourism market.

\section{The Current Situation and Existing Problems in Rural Tourism Products Supply}

China's rural tourism development is relatively late, rising in the late 1980s. In recent years, with the active support of the government and the vigorous promotion of tourism enterprises, rural tourism has achieved some success. China's rural areas are rich in natural scenery and historical and cultural resources with distinctive geographical features. Gucheng ancient town, garden architecture, farming civilization, ethnic customs, eating habits are relatively well preserved, the advantages of tourism resources are more obvious. With the development of rural tourism products developers to increase, the supply of rural tourism products in a substantial increase in the number of formed a certain scale. According to the different resources used by the products, the rural tourism products in our country can be divided into four categories, that is, the farmhouse leisure type, the traditional 
culture type, the village ancient town type and the leisure vacation type. The basic elements of rural tourism products include rural natural environment, flowers and trees, fruit and vegetable picking, agricultural production, folk customs, food culture, folk art and so on [2].

At present, most of the rural tourism products provided by tourism service enterprises are mainly in the forms of "group, package price, sightseeing, standard" and so on. First of all, the rural tourism products in all regions of China mainly provide rural accommodation and enjoy the natural scenery, with "farm music" as the main manifestation. Tourism tourism products occupy a dominant position in China's rural tourism products. The proportion of sports, leisure and entertainment, agricultural popular science education and other special tourism products in rural areas is relatively small. Second, the proportion of group travel is larger, the proportion of individual tourists travel needs to be improved. Lastly, the travel packages provided by the travel agencies to tourists are mainly in the form of all-inclusive package, with a small proportion of flexible packages and special services. From the supply side, China's rural tourism product type is monotonous, the product structure is not balanced.

On the one hand, China's current rural tourism product development process, due to the lack of extensive field research and scientific planning programs, and difficult to take into account the long-term interests, resulting in blind imitation, disorderly planning and arbitrarily draw or even copy other rural tourism development model phenomenon, eventually leading to a strong homogeneity of rural tourism products. On the other hand, many local governments and rural tourism developers did not really recognize the nature of rural tourism, mistakenly think that rural tourism activities are engaged in "farm music", did not fully tap other local tourism resources, resulting in the characteristics of tourism products are not prominent, personality Not strong. The lack of features and personality of the tourist products can easily be copied and imitation, resulting in a large number of our country's rural tourism products with a higher degree of homogeneity. The strong homogeneity of rural tourism products greatly reduces the competitiveness of products and makes a large number of domestic tourists outflow [3].

On the one hand, due to the fact that the development and research of rural tourism in our country is still in its infancy, the higher-level managerial talent developed for rural tourism is relatively inadequate. At present, most of the service personnel and managers engaged in rural tourism in our country are those who originally engaged in agricultural work, production, processing or marketing. They have little understanding of tourism and related professional knowledge, and have relatively little experience and experience in management of tourism development and tourism services, Lack of a sense of service, service concept and service skills. On the other hand, most of the rural tourism service personnel in our country have not undergone professional training, and although some have training experiences, the training time is relatively short, not enough norms and systems, and not enough service knowledge and service skills should be obtained. The lack of service awareness, service concept and service skills have seriously affected the service quality of rural tourism and damaged the image of tourist destination.

\section{Countermeasures to Promote the Supply-side Reform of China's Rural Tourism Products}

For a long time, rural tourism products are still mainly rural tourism and rural accommodation, single product structure, tourism product system short board. In order to promote the supply side reform of rural tourism products in China, we must enrich the types of rural tourism products and optimize the structure of tourism products. To this end, we must develop rural tourism products that can meet different levels of demand. At present, our country has entered the era of mass tourism, tourism has become increasingly necessities from luxury goods, as ordinary consumer goods into ordinary people's homes. This means that the development of rural tourism products, not only have to meet the high-income high-level, refined tourism products, but also have to meet the consumer needs of ordinary people travel products. Second, we must create a diversified rural tourism product mix. At present, it is urgent to change the structure of the traditional single tourism and tourism product and gradually improve the diversified rural tourism product structure such as holiday, exploration, sports and science popularization, and upgrade it to a compound rural tourism product 
structure based on sightseeing and vacation type [4].

In recent years, tourism development has laid emphasis on the benefits it has gained in the development process. It has paid insufficient attention to the building of personalized products and the enhancement of product competitiveness, which seriously hindered the development of rural tourism. Thus, to create personalized products, enhance product competitiveness has become an important part of the reform of rural tourism product supply side. To this end, first, multi-angle, multi-directional in-depth exploration of rural tourism product "farming" characteristics, to avoid homogenization. However, in view of the low level of development, the homogeneity of rural tourism products is more serious. Therefore, it is necessary to strengthen the characteristics of local folk culture, special properties, agricultural bases, forestry development and water conservancy construction in different regions Resources development, make enough "agriculture" word articles, design batch can fully demonstrate the knowledgeable, interesting, competitive, entertaining and participatory modern agriculture sightseeing tours, rural life experience tour, country folk custom travel and other personalities Rural tourism products, thereby enhancing product competitiveness. Second, carry forward the craftsmanship, attention to detail and taste. Premier Li Keqiang first proposed a "craftsman spirit" in the "Report on the Work of the Government" done in the 2016 National "Two Conferences" to encourage enterprises to carry out personalized customization [15]. Therefore, we should vigorously carry forward the "craftsmanship", select different topics or ways, pay attention to every detail of the product development process, carefully dig and give different connotation and characteristics of the product, highlighting each product's personality, taste and charm, try to Do "I have no people, people have me gifted, gifted people I special, people I am fine." Here's "fine" is well-designed, intensive, excellence.

In rural tourism development, local residents are the main providers of tourism services, the lack of specialized management and service personnel, seriously affecting the quality of service of rural tourism. Therefore, paying attention to the construction of tourism professionals and improving the quality of service are one of the important tasks in the supply side reform of rural tourism products. To this end, we must strengthen the training of practitioners. Training, not only to improve their basic level of culture, but also to cultivate their sense of service and ideas to promote them to form a good service habits. In addition, there is a special emphasis on training in professional services skills such as basic etiquette, basic tourism knowledge, room service skills and tour guide skills. Second, to increase cooperation with tourism institutions. Rural tourism destination should establish a long-term cooperation and win-win relationship with tourism colleges and universities. Rural tourism destinations can be regularly selected outstanding performance practitioners to travel colleges to study or further training, but also can be used as a tourism college extracurricular practice teaching and research base, tourism management and other related professional students to absorb this internship, research and carry out marketing practice activities. This kind of cooperation is of great significance to the training and introduction of tourism professionals in rural tourism destinations [5].

China's rural tourism resources are more adequate, but the cultural connotation is not enough. At present, the cultural industry and tourism industry have gradually become the green sunrise industry in each country or region that attaches great importance to development. The combination and development of "Wen-brocade" and the two major industries are of great significance to the structural transformation of China's rural tourism industry. It will also play an extremely important role in the supply-side reform of China's rural tourism products. To this end, we must accelerate the application of advanced science and technology to the development of rural tourism products. The integration of cultural industry and tourism industry needs the support of high and new technology. On the basis of the original rural tourism resources, modern and high-tech science and technology are used to preserve the rural nature and authenticity of products, to integrate into the local special culture, to develop a profound cultural connotation and to have more Strong participatory, interactive rural tourism products. Second, we must increase the government's policy support. Rapid industrial integration and development can not be separated from the government's supportive policies. The government may, at its discretion, appropriately relax its control over the integration 
of "brigade brigades" and further introduce relevant policies to encourage industrial integration. In addition, due to the trend of development in the integration of culture industry and tourism industry, the government should formulate relevant policies in keeping with the principle of flexibility and dynamics in order to keep pace with the times.

\section{Conclusions}

The Supply Side Reform of Rural Tourism Products Assists in the Transformation and Upgrading of Rural Tourism and the Tourism Poverty Alleviation. At present, the supply of rural tourism products in our country is more monotonous in product supply and the structure is not reasonable; the products are of high homogeneity; the service quality is not high; the image of tourism destination is not clear enough; the product culture is less rich and the product experience value is not high. Therefore, we must enrich product categories, optimize the structure of tourism products; create personalized products, enhance product competitiveness; emphasis on the construction of rural tourism professionals, improve service quality; strengthen the "cultural tourism" integration of the two industries to enhance the product culture connotation; attention Visitors experience, improve product experience value.

\section{Acknowledgements}

The project source: the university-level research projects of China west normal university (rural tourism research based on the agricultural supply-side reform — take Sichuan province for exa mple) The project number: 416492.

\section{References}

[1] Li Zhiqiang, Zhu Xianghui. Study on the Transformation and Upgrading of Rural Tourism Products in Jiangxi Province in the Perspective of Supply-side Reform [J]. Old district building. 2016 (16): 15 21.

[2] Xu Jinhai, Xia Jiechang. Supply-side reform thinking to promote China's tourism product system construction [J]. Hebei Academic Journal. 2016 (03): 48 49.

[3] LI Haifeng. Application of experiential marketing in rural tourism product development [J]. China Management Informatization. 2014 (03): 93 97.

[4] Huang Cuizhe. SWOT analysis of rural tourism and the concept of tourism product development [J]. Anhui Agricultural Sciences. 2011 (14): 102 105.

[5] Zhang Yurong. Rational thinking on the development of rural tourism in Chongqing as a whole: from the perspective of rural cultural and creative tourism products [J]. Agricultural Economy, 2010 (10): 43 47.

[6] Mao Yong. Rural tourism product system and development [J]. Journal of South Central University for Nationalities. 2009 (02): 66 72. 